\title{
Initial precipitation and hardening mechanism during non-isothermal aging in an $\mathrm{Al}-\mathrm{Mg}-\mathrm{Si}-\mathrm{Cu}$ 6005A alloy
}

\author{
Wenchao Yang ${ }^{a, b, *}$, Shouxun $\mathrm{Ji}^{b}$, Lanping Huang ${ }^{c}$, Xiaofei Sheng ${ }^{a}$, Zhou Li $^{a}$, Mingpu Wang ${ }^{a}$ \\ ${ }^{a}$ School of material Science and Engineering, Central South University, Changsha, 410083, China \\ brunel Centre for Advanced Solidification Technology (BCAST), Brunel University, Uxbridge, UB8 3PH, UK \\ 'State Key Laboratory of Powder Metallurgy, Central South University, Changsha, 410083, China
}

\begin{abstract}
A B S T R A C T
The characterization of precipitation and hardening mechanism during non-isothermal aging had been investigated using high resolution transmission electron microscopy for an $\mathrm{Al}-\mathrm{Mg}-\mathrm{Si}-\mathrm{Cu}$ 6005A alloy. It was proposed that the needle-shaped $\beta^{\prime \prime}$ precipitates with a three-dimension coherency strain-field and an increased number density in the Al matrix provided the maximum strengthening effect for the Al-Mg-Si-Cu 6005A alloy. Simultaneously, it was also found that the formation and evolution of clusters in the early precipitation were associated with the vacancy binding energy, during which $\mathrm{Si}$ atoms played an important role in controlling the numbers density of $\mathrm{Mg} / \mathrm{Si}$ co-clusters, and the excess $\mathrm{Si}$ atoms provided the increased number of nucleation sites for the subsequent precipitates to strengthen and improve the precipitation rate. Finally, based on the experimental observation and theoretical analysis, the precipitation sequence during the early precipitation in the Al-Mg-Si-Cu 6005A alloy was proposed as: supersaturated solid solution $\rightarrow$ Si-vacancy pairs, Mg-vacancy pairs and $\mathrm{Mg}$ clusters $\rightarrow$ Si clusters, and dissolution of $\mathrm{Mg}$ clusters $\rightarrow \mathrm{Mg}$ atoms diffusion into the existing $\mathrm{Si}$ clusters $\rightarrow \mathrm{Mg} / \mathrm{Si}$ co-clusters $\rightarrow$ GP zone.
\end{abstract}

\section{Introduction}

Al-Mg-Si alloys with $\mathrm{Cu}$ addition are widely used in industry owing to their excellent combination of mechanical properties, formability and corrosion resistance [1]. The precipitation strengthening of alloy has been well-studied because it forms the basis for a wide range of age-hardening alloys that are technologically important $[2,3]$. It has recognized that the metastable nano-particles precipitated from the matrix are critical for the precipitation strengthening $[4,5]$. The precipitation sequence in the $\mathrm{Al}-\mathrm{Mg}-\mathrm{Si}-\mathrm{Cu}$ alloys is generally described as [6,7]: supersaturated solid solution (SSSS) $\rightarrow$ clusters/GP zones $\rightarrow \beta^{\prime \prime}$ phase $\rightarrow \beta^{\prime} / Q^{\prime}$ phases $\rightarrow \beta / Q$ phases [8]. The clusters/GP zones are found as the aggregates of solute atoms with full coherency in the Al matrix. During the subsequent artificial aging, these clusters/GP zones serve as nucleation sites for $\beta^{\prime \prime}$ phase, which displays the needleshaped morphology along three $<100\rangle_{\mathrm{Al}}$ directions [9]. Then the $\beta^{\prime}$ and $Q^{\prime}$ phases are formed with rod-shaped morphology [10]. Finally, the equilibrium $\beta$ and $Q$ phases are precipitated 
with a $\mathrm{CaF}_{2}$ type face centered cubic (FCC) structure and a $\mathrm{Th}_{7} \mathrm{~S}_{12}$ type hexagonal close packed structure in this system, respectively $[11,12]$.

The evolution process between these metastable phases is very important to understand the hardening mechanisms during aging. Of which the formation of clusters/GP zones and $\beta^{\prime \prime}$ precipitates in the early stages of precipitation is particularly interested as it determines the final strengthening effect, which is naturally dependent on the microstructural morphology of precipitates. Therefore, a large amount of effort has been done to understand the nature and composition of these precipitates by Wanderka et al. [13], Vissers et al. [14], Chen et al. [15] and Marioara et al. [16] in Al-Mg-Si based alloys. It should be noted that the characterizations for $\beta^{\prime \prime}$ phase or following metastable phases are relatively easy because they can basically be identified as specific crystal structures and compositions. However, it is relatively difficult to analyze the early evolution process from the clusters to GP zones because they have only a few nanometers in size with undefined crystal structures and varied compositions. Although the clusters/GP zones have been studied by the three-dimensional atom probe (3DAP) [17] and the atom probe field ion microscopy (APFIM) technologies [18,19], the detailed evolution process is still not fully understood. Therefore, it is necessary to find more evidence to establish the nature of the precipitates in the early stages of precipitation.

Non-isothermal heat treatment at a given heating rate is a widely used method to study the precipitation in $\mathrm{Al}-\mathrm{Mg}-\mathrm{Si}$ based alloys [20]. During the heating ramp of multistep heat treatments, all parameters of the precipitation process including diffusion, driving force and nucleation barriers evolve simultaneously. Precipitates that nucleate at a given time may be destabilized at the next time step. Thus, the dissolution of metastable phases can occur concurrent with precipitation of more stable phases. As such, a non-isothermal temperature history may activate the precipitation of several metastable phases in a complex manner [21]. Therefore, non-isothermal heat treatment is also applied in the welding filed to indentify the phases at different positions [22] or in the glass research for the thermal stability and crystallization kinetics [23].

In this paper, non-isothermal aging heat treatment was used in the Al-Mg-Si-Cu 6005A alloy to detail a correlation between the precipitation hardening and the microstructural evolution. Based on the experimental evidence and theoretical analysis, the formation and evolution of clusters in the early stages of precipitation were assessed in terms of vacancy binding energy, followed by the deduction of the early precipitation sequence in the Al-Mg-Si-Cu 6005A alloy.

\section{Experimental Methods}

The Al-Mg-Si-Cu 6005A alloy was received in the form of as-extruded sheets with a cross-section of $150 \mathrm{~mm}$ wide and $5 \mathrm{~mm}$ thick. The chemical composition of alloy was analyzed and shown in Table 1. Prior to the heat treatment, the as-extruded sheets were cut into small samples with $5 \times 20 \times 20 \mathrm{~mm}$ in size. Then the samples were heated up to $550{ }^{\circ} \mathrm{C}$ and maintained at this temperature for 1 hour to achieve a complete solution, followed by an immediate water quenching in a tank to room temperature $\left(20^{\circ} \mathrm{C}\right)$. In order
Table 1-Chemical composition of the Al-Mg-Si-Cu $6005 \mathrm{~A}$ alloy used in the current study.

\begin{tabular}{lccccccc} 
6005A & $\mathrm{Mg}$ & $\mathrm{Si}$ & $\mathrm{Cu}$ & $\mathrm{Cr}$ & $\mathrm{Mn}$ & $\mathrm{Fe}$ & $\mathrm{Al}$ \\
\hline Wt.\% & 0.65 & 0.73 & 0.13 & 0.13 & 0.17 & 0.15 & 98.04 \\
At.\% & 0.72 & 0.70 & 0.06 & 0.07 & 0.08 & 0.07 & 98.29 \\
\hline
\end{tabular}

to minimize the influence of natural aging on the microstructures after quenching, non-isothermal aging treatment was immediately performed within 1 minute by heating the solution-treated samples to different temperatures at a rate of $10{ }^{\circ} \mathrm{C} / \mathrm{min}$.

Vickers hardness was measured at $2 \mathrm{~kg}$ load for $15 \mathrm{~s}$ using a HV-5 sclerometer. Five indentations were performed for each sample and the average value was taken as the measurement. Based on the hardening curve, typical specimens at the different temperatures were selected for the detailed transmission electron microscopy (TEM) and high resolution transmission electron microscopy (HRTEM) examination. The specimens for TEM were prepared by a standard electro-polishing procedure. The electrolytic solution was a mixture of nitric acid and methyl alcohol (2:8). The polishing was operated at $22 \mathrm{~V}$ from $-20^{\circ} \mathrm{C}$ to $-30^{\circ} \mathrm{C}$. A JEOL-2100 F HRTEM was used for the microstructure investigation. The operation voltage was set at $200 \mathrm{kV}$ during experiments.

\section{Results}

\subsection{The Hardening Curve during Non-isothermal Aging}

Fig. 1 showed the hardness of Al-Mg-Si-Cu 6005A alloy aged at different temperatures at a constant heating rate of $10^{\circ} \mathrm{C} / \mathrm{min}$. The hardness was only $55.2 \mathrm{HV}$ under the supersaturated solid solution state. It was gradually increased to $63.5 \mathrm{HV}$ at $100{ }^{\circ} \mathrm{C}$ and subsequently dropped to $60.1 \mathrm{HV}$ at $160^{\circ} \mathrm{C}$, followed by a rapid increase to the maximum hardness of $83.5 \mathrm{HV}$ at $250^{\circ} \mathrm{C}$. With the further increase of the aging temperature, the hardness was rapidly fallen to $59.6 \mathrm{HV}$ at $300{ }^{\circ} \mathrm{C}$ and then gradually decreased to $57.0 \mathrm{HV}$ at $480^{\circ} \mathrm{C}$. The experimental results clearly

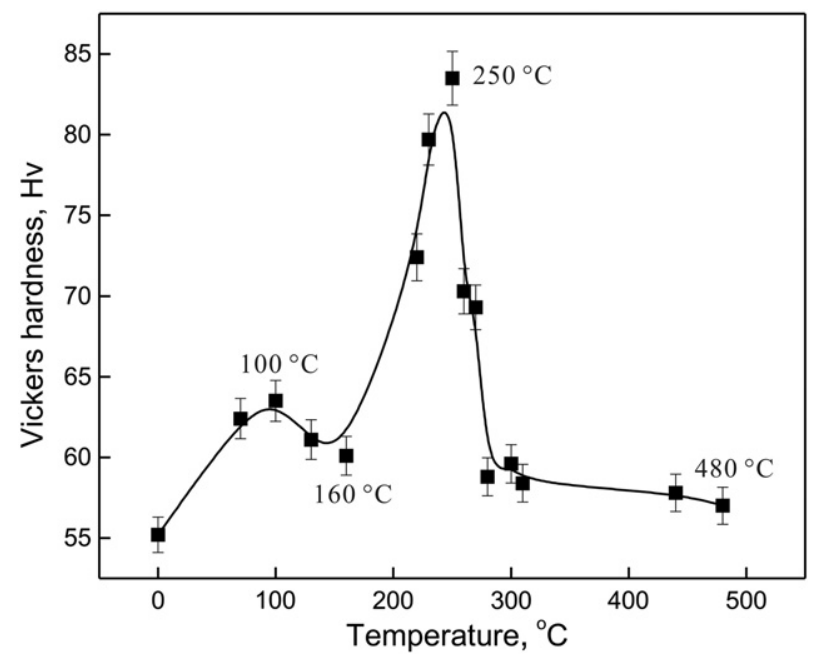

Fig. 1 - Non-isothermal age-hardening curve of the 6005A alloy heated to different temperatures at $10^{\circ} \mathrm{C} / \mathrm{min}$. 
confirmed the existence of double peak of hardness during non-isothermal aging. The typical temperatures of $100^{\circ} \mathrm{C}$, $160^{\circ} \mathrm{C}, 250^{\circ} \mathrm{C}$ and $480^{\circ} \mathrm{C}$ represented the different stages of non-isothermal aging based on the significant variation of the hardness. Therefore, the specimens aged at $100{ }^{\circ} \mathrm{C}, 160^{\circ} \mathrm{C}$, $250^{\circ} \mathrm{C}$ and $480^{\circ} \mathrm{C}$ were selected for further TEM and HRTEM examinations.

\subsection{Microstructural Evolution}

Fig. 2 showed the bright field TEM images with the corresponding selected area diffraction patterns (SADP) and the HRTEM images with the corresponding Fast Fourier Transformation (FFT) patterns for the alloy aged at different temperatures. In Fig. 2a, the specimen was heated to $100{ }^{\circ} \mathrm{C}$, which corresponded to the first peak of hardness. No obvious precipitates were observed in the TEM image. Meanwhile, apart from the diffraction spots from the $\mathrm{Al}$ matrix under the $[001]_{\mathrm{Al}}$ zone axis, no any excess diffraction reflections were found in the corresponding SADP. This indicated that the bright field TEM image was not capable of examining the formation of precipitates at the early stages of precipitation. However, it was clear that the alloy displayed a slight peakvalue hardness at $100^{\circ} \mathrm{C}$ (Fig. 1), which indicated that some clusters might have been precipitated from the $\mathrm{Al}$ matrix so that the hardness increased. Therefore, the same sample was further assessed using HRTEM. In Fig. 2b, the HRTEM image confirmed that some clusters had been presented and displayed some typical strain-field contrasts, which were marked by the black circles in the HRTEM image. Then it was also found that these clusters were clearly buried and fully coherent with the Al matrix.

Fig. $2 \mathrm{c}$ and $d$ showed the TEM and the corresponding HRTEM images for the alloy aged at $160{ }^{\circ} \mathrm{C}$. It was found that the microstructure observed in Fig. $2 \mathrm{c}$ was very similar to that in Fig. 2a, in which no any excess diffraction streaks from the precipitates were seen in the corresponding [001] $]_{\mathrm{Al}} \mathrm{SADP}$. However, the difference in the microstructure could be detected
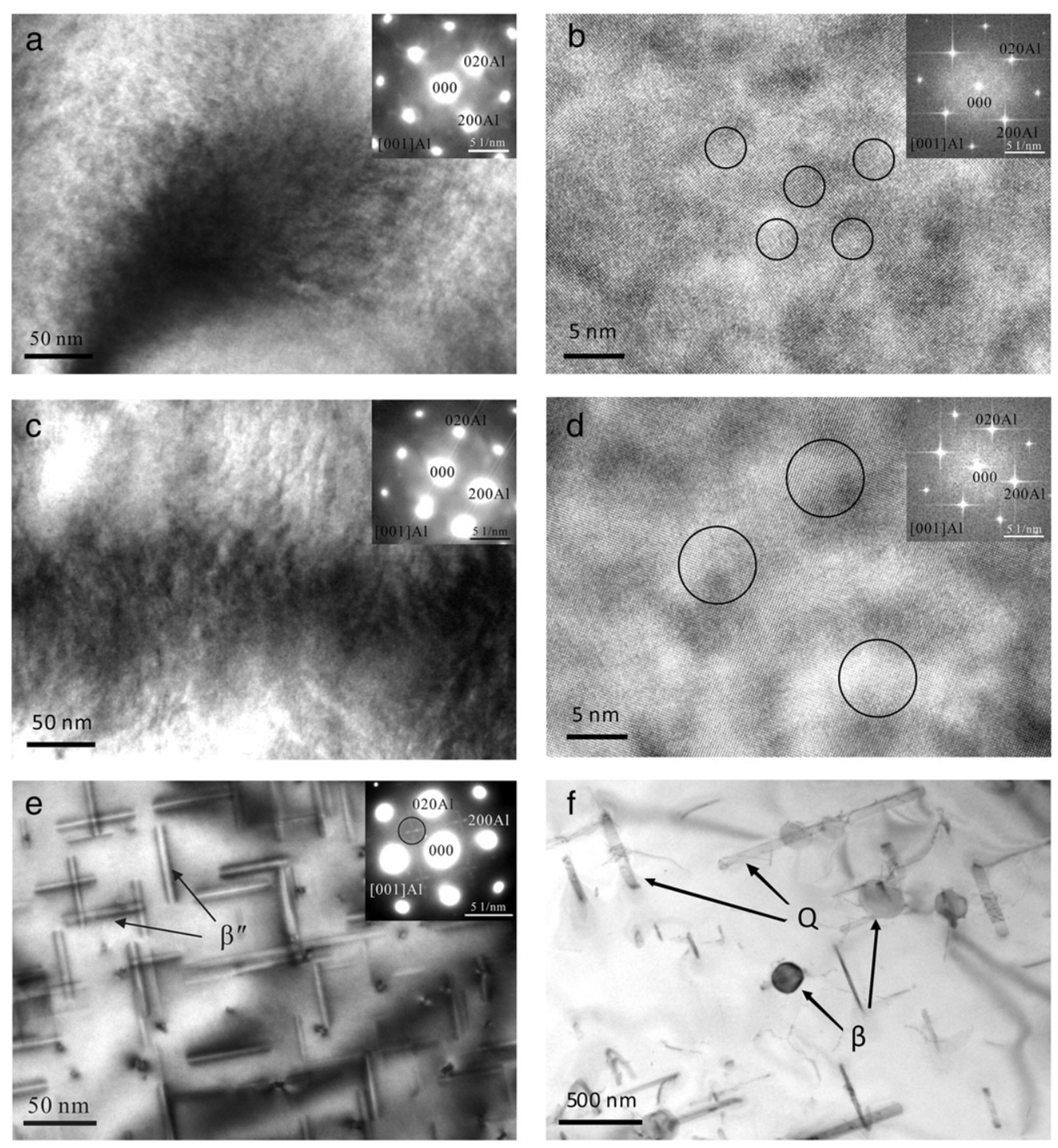

Fig. 2 - TEM and HREM images with the corresponding SADPs and FFT patterns at different aging temperatures of 6005A alloy. (a, b) $100^{\circ} \mathrm{C}$; (c, d) $160^{\circ} \mathrm{C}$; (e) $250^{\circ} \mathrm{C}$; (f) $480^{\circ} \mathrm{C}$. SADPs and FFT patterns are given as inserts. The circles in panels b and $d$ indicate the strain-field contrasts from some clusters. Please note the difference in the scale bars used in panels e and $\mathrm{f}$. 
in the HRTEM image as shown in Fig. 2d. Some clusters were also observed in the strain-field contrasts, marked by the black circles in the HRTEM image. In comparison with the similar results in Fig. 2b, these strain-fields in Fig. 2d showed a larger size and a lower number density. This might indicate that some clusters precipitated at less than $160^{\circ} \mathrm{C}$ had been dissolved into the $\mathrm{Al}$ matrix when the sample was heated up to $160^{\circ} \mathrm{C}$. As a result, a large number of free solute atoms were formed in the Al matrix. Finally, these free solute atoms would diffuse into the remaining clusters to grow the clusters.

Fig. 2e showed the corresponding TEM and SADP of alloy aged at $250{ }^{\circ} \mathrm{C}$ to reach its peak-value of hardness. It was found that a number of needle-shaped $\beta^{\prime \prime}$ precipitates in 60 $80 \mathrm{~nm}$ long was evenly distributed in the Al matrix along three $\langle 100\rangle_{\mathrm{Al}}$ directions. And, these needle-shaped $\beta^{\prime \prime}$ precipitates showed a clear coherency strain-field in the [100] $]_{\mathrm{Al}}$ and $[010]_{\mathrm{Al}}$ directions, which were marked by the arrows in Fig. 2e. Meanwhile, some typical "cross-shaped" diffraction streaks were observed in the corresponding $[001]_{\mathrm{Al}} \mathrm{SADP}$, which were marked by the circle in the image. These "cross-shaped" diffraction streaks had been identified from the 12 variants of $\beta^{\prime \prime}$ precipitates in our previous research [9].

The TEM image in Fig. $2 \mathrm{f}$ was from the alloy heated to $480{ }^{\circ} \mathrm{C}$ at a rate of $10^{\circ} \mathrm{C} / \mathrm{min}$ and the corresponding hardness was $57 \mathrm{HV}$ (Fig. 1). This temperature was generally related to the precipitation of stable $Q$ and $\beta$ phases [7]. The micrograph showed that the stable $Q$ and $\beta$ phases had been formed with the coarser sizes and a lower number density in comparison with $\beta^{\prime \prime}$ precipitates (please note the difference in the scale bars used in Fig. 2e and f). The strengthening effect of the stable $Q$ and $\beta$ phases was much less as the increased size in the experimental alloy. This was in good agreement with the works carried out by Chakrabarti and Laughlin [7]. At the same time, the result also further confirmed that the increased temperature could generate the precipitation of stable $Q$ and $\beta$ phases.

In addition, it should be realized that, during the microstructure evolution process in the non-isothermal aging, these needle-shaped $\beta^{\prime \prime}$ phases formed at $250^{\circ} \mathrm{C}$ would gradually coarsen and then dissolve with the increase of temperature. Simultaneously, the following $\beta^{\prime}$ or $\mathrm{Q}^{\prime}$ phases would be precipitated in the microstructure. Both of them resulted in the decrease of hardness in Fig. 1 between $250^{\circ} \mathrm{C}$ and $400{ }^{\circ} \mathrm{C}$. However, the initial precipitation was only considered in this paper, therefore, the detailed microstructure evolution between $250{ }^{\circ} \mathrm{C}$ and $400{ }^{\circ} \mathrm{C}$ did not present here. The similar microstructural evolution in the same experimental alloy including the precipitates type and their number density difference may refer to [24].

\section{Discussion}

\subsection{Strengthening from the $\boldsymbol{\beta}^{\prime \prime}$ Precipitates}

The results from non-isothermal aging confirmed that the needle-shaped $\beta^{\prime \prime}$ precipitates provided the most significant strengthening effect in the Al-Mg-Si-Cu 6005A alloy. This indicated that the $\beta^{\prime \prime}$ precipitates were the most effective obstacle to block the movement of dislocations in the Al matrix.

Fig. 3a and $b$ displayed two enlarged bright field TEM contrast images from an embedded $\beta^{\prime \prime}$ precipitate along the
$[001]_{\mathrm{Al}}$ direction and a lying $\beta^{\prime \prime}$ precipitate along the $[010]_{\mathrm{Al}}$ direction in the same $(001)_{\mathrm{Al}}$ plane, respectively. It was seen that the embedded $\beta^{\prime \prime}$ precipitate presented a lobe-shaped contrast, and the lying $\beta$ " precipitate exhibited a needle-shaped contrast. The corresponding intensity/distance distribution spectrums were also given in Fig. $3 a$ and $b$ as inserts. According to the strain-field contrasts, it was anticipated that a needle-shaped $\beta^{\prime \prime}$ precipitate might represent two coherency strain-fields in three-dimensional space: one was parallel to its cross-section, and the other was vertical to its cross-section. In other words, the needle-shaped $\beta^{\prime \prime}$ precipitate had a three-dimensional coherency strain-field in the Al matrix.

In order to support this hypothesis, HRTEM observations were further performed for the embedded $\beta^{\prime \prime}$ precipitate and the lying $\beta^{\prime \prime}$ precipitate. Fig. $3 c$ presented the typical HRTEM image from the embedded $\beta^{\prime \prime}$ precipitate. It was seen that the embedded $\beta^{\prime \prime}$ precipitate had the orientation relationships with Al matrix as: $(010)_{\beta}{ }^{\prime \prime} / /(001)_{\mathrm{Al}},[001]_{\beta^{\prime \prime}} / /[1 \overline{3} 0]_{\mathrm{Al}}$, and $[100]_{\beta^{\prime \prime}} / /$ $[320]_{\mathrm{Al}}$, as shown in Fig. 3c. According to the results obtained from the previous research [9], this embedded $\beta^{\prime \prime}$ precipitate actually belonged to the variant 3 in 12 variants of $\beta$ " precipitates. Further, based on the lattice parameters and orientation relationships, the misfits between $\beta^{\prime \prime}$ precipitate and two $\{200\}_{\mathrm{Al}}$ planes of the $\mathrm{Al}$ matrix in the $[001]_{\mathrm{Al}}$ direction were also calculated as $4.3 \%$ and $5.4 \%$, respectively. The small misfits provided strong suggestions of the existence of a basic coherency strain-field around this embedded $\beta^{\prime \prime}$ precipitate. Fig. $3 d$ displayed the HRTEM image of a lying $\beta^{\prime \prime}$ precipitate along the $[010]_{\mathrm{Al}}$ direction, as marked by the white dash lines. Some typical diffraction streaks from this lying $\beta$ " precipitate were present in the corresponding FFT patterns and marked by the circle. These diffraction characterizations confirmed that this lying $\beta^{\prime \prime}$ precipitate should belong to the variant 5 or 6 in 12 variants of $\beta^{\prime \prime}$ precipitates [9]. At the same time, it was clear that the lying $\beta^{\prime \prime}$ precipitate was basically coherent with the $\mathrm{Al}$ matrix along its long axis direction because the $b$-axis parameter of $\beta^{\prime \prime}$ precipitate (about $0.405 \mathrm{~nm}$ ) almost equaled to the lattice parameter of $\mathrm{Al}$ matrix.

It was generally believed that the alloy could be strengthened by the interaction of dislocations movement and the precipitates. Therefore, the existence of the three-dimensional coherency strain-field around the needle-shaped $\beta^{\prime \prime}$ precipitates would be the most notable obstacles for the dislocation movement because it provided larger obstacles in comparison with other metastable or stable phases that had semi-coherent or incoherent interfaces with the Al matrix. The detailed interface analysis using HRTEM for the metastable phases could be found in Ref. [24]. Regarding further combination of the results in reference [24] and the number density difference between precipitates in Fig. 2, it was believed that the $\beta$ " precipitates with a three-dimensional coherency strain-field and an increased number density could provide the maximum strengthening effect in the Al-Mg-Si-Cu 6005A alloy.

\subsection{Formation and Evolution of the Clusters in the Early Stages of Precipitation}

During the non-isothermal aging treatment, the microstructural evolution at different temperatures had showed the existence of transformation between the metastable clusters (Fig. 2a-d). The 

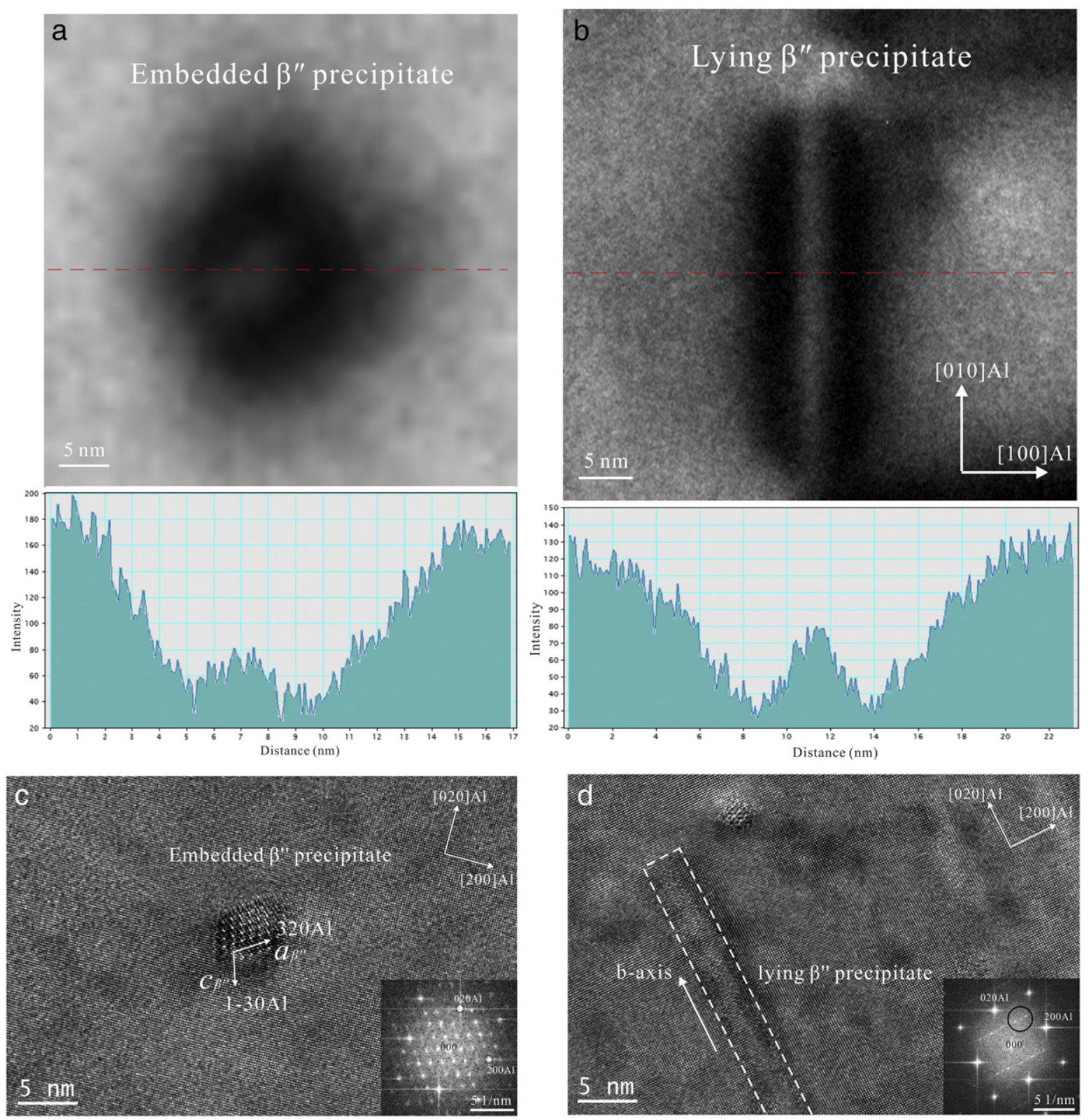

Fig. 3 - Strain-field contrasts and HRTEM observations from the needle-shaped $\beta$ " precipitates. (a) Enlarged image of an embedded $\beta$ " precipitate along the $[001]_{\mathrm{Al}}$ direction and the corresponding intensity/distance distribution spectrum across this precipitate, which presents the lobe-shaped coherency strain-field contrast. (b) Enlarged image of a lying $\beta$ " precipitate along the $[010]_{\mathrm{Al}}$ direction and the corresponding intensity/distance distribution spectrum across this precipitate, which presents the needle-shaped coherency strain-field contrast. (c, d) The HRTEM images of this embedded and lying $\beta$ " precipitates, respectively. The corresponding FFT patterns are located at the lower right corner as inserts.

early decomposition from SSSS in the Al-Mg-Si-Cu alloy can be described as: SSSS $\rightarrow$ clusters. And, the results from the previous studies [17-19] supported that there were basically three main clusters in the early precipitation, i.e., Mg clusters, $\mathrm{Si}$ clusters and $\mathrm{Mg} / \mathrm{Si}$ co-clusters. Although Edwards et al. [17] proposed an initial clustering sequence as: SSSS $\rightarrow$ clusters of $\mathrm{Si}$ atoms and clusters of $\mathrm{Mg}$ atoms $\rightarrow$ dissolution of $\mathrm{Mg}$ clusters $\rightarrow$ formation of $\mathrm{Mg} / \mathrm{Si}$ co-clusters, the influence of vacancies was not considered and the role of the vacancies still remained unknown. As it was almost certain that the excess vacancies quenched-in from solution treatment temperatures were responsible for the formation of clusters or GP zones in the $\mathrm{Al}$ alloy. And, the higher solute-vacancy binding energy (SVBE) was beneficial to attract vacancies to form atoms-v pairs. Therefore, how to define the early precipitation process in terms of binding energy was important and significant to understand the whole strengthening mechanism in the Al$\mathrm{Mg}-\mathrm{Si}-\mathrm{Cu}$ 6005A alloy. In addition, because the binary alloy phase diagram (BAPD) as a very useful tool could be used to describe the solid solubility of solute atoms in the $\mathrm{Al}$ matrix at any temperature, it was thus used in association with SVBE to describe the formation and evolution of clusters. 
Table 2 presented the SVBE for different solute atoms in the FCC Al matrix reported in literature [25-28]. The SVBE was $0.23 \mathrm{eV}$ for $\mathrm{Si}$ atoms and $0.18 \mathrm{eV}$ or $0.19 \mathrm{eV}$ for $\mathrm{Mg}$ atoms. This confirmed that the SVBE for Si atoms was larger than that for $\mathrm{Mg}$ atoms. As shown in Table 1, the atomic fractions of $\mathrm{Mg}$ and $\mathrm{Si}$ elements had no obvious difference in the Al-Mg-Si-Cu $6005 \mathrm{~A}$ alloy. Therefore, the higher value of SVBE indicated that the concentration of vacancies binding to $\mathrm{Si}$ atoms should be larger than that binding to $\mathrm{Mg}$ atoms when the $\mathrm{Al}-\mathrm{Mg}-\mathrm{Si}-\mathrm{Cu}$ $6005 \mathrm{~A}$ alloy was quenched to form a supersaturated solid solution. As a result, apart from a large number of vacancies in the Al matrix, the Mg-v pairs and $\mathrm{Si}-\mathrm{v}$ pairs might also be presented in the matrix after quenching. This process was similar to the precipitation of $\mathrm{Cu}-\mathrm{v}$ pairs in Al-Cu alloys [29], where $\mathrm{Cu}-\mathrm{v}$ pairs were presented immediately after quenching. The vacancies in the Al-Cu alloy were gradually released during aging to form $\mathrm{Cu}$ clusters and/or GP zones. In addition, the previous research also indicated that a number of $\mathrm{Mg}$ clusters could be precipitated immediately during quenching in the $\mathrm{Al}-\mathrm{Mg}-\mathrm{Si}$ alloy with the excess $\mathrm{Si}$ atoms [18]. Therefore, three types of microstructures might be formed after quenching: $\mathrm{Mg}-\mathrm{v}$ pairs, $\mathrm{Si}-\mathrm{v}$ pairs and $\mathrm{Mg}$ clusters in the Al-Mg-Si-Cu 6005A alloy. Similar to the formation of $\mathrm{Cu}$ clusters in $\mathrm{Al}-\mathrm{Cu}$ alloys, a large number of vacancies could be gradually released during aging to form Si clusters. However, according to the BAPDs in Al-Mg and Al-Si alloys as shown in Fig. 4, which were calculated by the CALPHAD thermodynamic software, the solid solubility of $\mathrm{Mg}$ atoms in the $\mathrm{Al}$ matrix was located between 1.4 at.\% and 2.6 at.\% at the $100{ }^{\circ} \mathrm{C}-160{ }^{\circ} \mathrm{C}$ in Fig. $4 \mathrm{a}$, but the solid solubility of $\mathrm{Si}$ atoms in the $\mathrm{Al}$ matrix was less than 0.001 at $\%$ in the same temperature range in Fig. $4 \mathrm{~b}$. Therefore, the Mg clusters formed during quenching could be re-dissolved into the Al matrix to produce a large number of free $\mathrm{Mg}$ atoms once the thermodynamics and kinetics condition were satisfied whereas the Si clusters were reserved with aging process. It should be noted that although there was also a certain solubility below $100^{\circ} \mathrm{C}$, these $\mathrm{Mg}$-clusters might have no enough kinetics to dissolve due to the inadequate dynamic condition (the lower temperature and the shorter time). Because the free $\mathrm{Mg}$ atoms had much stronger interaction with $\mathrm{Si}$ atoms than that with $\mathrm{Al}$ atoms, they could diffuse into the existing Si clusters to form the $\mathrm{Mg} / \mathrm{Si}$ co-clusters, and subsequently transformed into GP zones. This evolution process had been verified by using Monte Carlo simulation for $\mathrm{Al}$ alloys [30]. In addition, this phenomenon has been confirmed by the HRTEM observations (Fig. 2), which indicated that these re-dissolved clusters might be $\mathrm{Mg}$ clusters at the increased temperature in the non-isothermal aging treatment.

Table 2 - Binding energy between different solute atoms and vacancies in the FCC Al.

\begin{tabular}{ccc} 
Element & $\begin{array}{c}\text { Solute-vacancy } \\
\text { binding energy }(\mathrm{eV})\end{array}$ & References \\
\hline $\mathrm{Mg}$ & 0.19 & {$[25]$} \\
& 0.18 & {$[26]$} \\
$\mathrm{Si}$ & 0.23 & {$[25]$} \\
& 0.30 & {$[27]$} \\
$\mathrm{Cu}$ & 0.05 & {$[25,28]$} \\
\hline
\end{tabular}
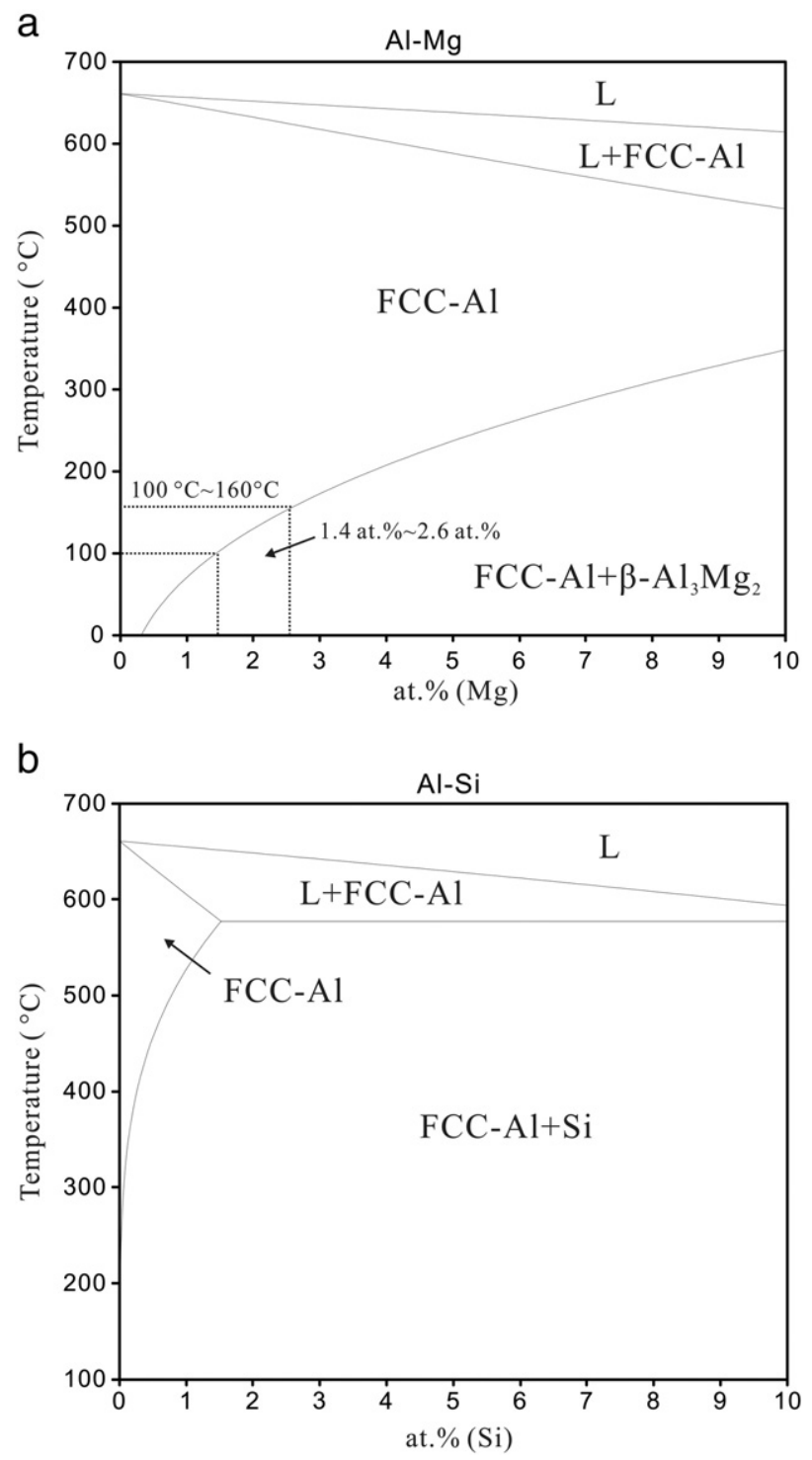

Fig. 4 - Equilibrium phase diagrams of (a) Al-Mg and (b) Al-Si binary alloy, calculated by the CALPHAD thermodynamic software.

However, $\mathrm{Cu}$ atoms might have no obvious effect on the early precipitation of Al-Mg-Si-Cu 6005A alloy as the number of $\mathrm{Cu}-\mathrm{v}$ pairs was too low or they did not present in quenching. One reason was that $\mathrm{Cu}$ atoms had a much lower SVBE (Table 2) resulting in a weak attraction for these quenched vacancies in comparison with $\mathrm{Si}$ and $\mathrm{Mg}$ atoms. Therefore, the paucity of excess vacancies quenched-in from a solution treatment temperature could be bound to $\mathrm{Cu}$ atoms. Another reason was the dependence on a low atomic volume fraction in the experimental alloy (Table 1). As a result, a large number of $\mathrm{Cu}$ atoms could only exist in the $\mathrm{Al}$ matrix in the form of solid solution in the early stages of precipitation. Similarly, Edwards et al. [17] also found that the Cu atoms had no effect on the formation of $\mathrm{Mg}$ clusters and/or Si clusters in the Al0.89 at.\%Mg-0.76 at.\%Si-0.08 at.\%Cu alloy.

Furthermore, the concentration of vacancies combining with $\mathrm{Si}$ atoms in the $\mathrm{Al}-\mathrm{Mg}-\mathrm{Si}-\mathrm{Cu}$ alloy could be analyzed by a 
model proposed for the Al-Cu-Sn alloy [31]. The concentration of vacancies bound to $\mathrm{Si}$ atoms, $\mathrm{C}_{\mathrm{Si} \text {-v }}$ could be described as:

$$
C_{\mathrm{Si}-\mathrm{v}}=\frac{\frac{C_{\mathrm{Si}}}{C_{\mathrm{Mg}}} C_{\mathrm{v}} \exp \left(-\frac{\Delta B}{K T}\right)}{1+\frac{C_{\mathrm{Si}}}{C_{\mathrm{Mg}}} \exp \left(-\frac{\Delta B}{K T}\right)}
$$

where $C_{\mathrm{Mg}}$ and $C_{\mathrm{Si}}$ were the atomic fraction of $\mathrm{Mg}$ and $\mathrm{Si}$ atoms, respectively, $\Delta B$ was the difference between binding energies of a vacancy with two atoms, $C_{v}$ was the total concentration of quenched-in vacancies and independent of the aging temperature, $\mathrm{K}$ was the Boltzmann constant, and $\mathrm{T}$ was the solution temperature. Eq. (1) clearly suggested that the bigger the $C_{\mathrm{Si}}$ value, the higher the $C_{\text {Si-v }}$ concentration. This implied that $\mathrm{Si}$ atoms were easier to attract vacancies to form Si-v pairs, and the atomic fraction of $\mathrm{Si}$ atoms controlled the numbers of $\mathrm{Si}-\mathrm{v}$ pairs. Because the numbers of Si-v pairs was directly proportional with the numbers of $\mathrm{Mg} / \mathrm{Si}$ co-clusters, the $\mathrm{Si}$ atoms could play an important role in controlling the number density of $\mathrm{Mg} / \mathrm{Si}$ co-clusters. The excess $\mathrm{Si}$ atoms in $\mathrm{Al}-\mathrm{Mg}-\mathrm{Si}$ alloys provided the increased number of nucleation sites for the subsequent precipitates to strengthen and improve the precipitation rate. The similar results were also obtained using 3DAP and APFIM technologies in other Al-Mg-Si alloys to detect the influence of excess $\mathrm{Si}$ atoms $[4,17,32]$.

Finally, on the basis of the experimental results and theoretical understanding presented above, the microstructural evolution process from SSSS to GP zones in the early stages of precipitation could be modeled for the Al-Mg-Si-Cu 6005A alloy.
Fig. 5 displayed this model including some schematic diagrams in microstructural evolution process. According to this model, the precipitation sequence in the early stages of precipitation for the Al-Mg-Si-Cu 6005A alloy was deduced as: SSSS $\rightarrow \mathrm{Si}-\mathrm{v}$ pairs, Mg-v pairs and Mg clusters $\rightarrow$ Si clusters and dissolution of $\mathrm{Mg}$ clusters $\rightarrow \mathrm{Mg}$ atoms diffusion into the existing $\mathrm{Si}$ clusters $\rightarrow \mathrm{Mg} / \mathrm{Si}$ co-clusters $\rightarrow$ GP zones.

\section{Conclusions}

The non-isothermal aging hardening behavior has been investigated using TEM and HRTEM in the Al-Mg-Si-Cu 6005A alloy. The SVBE and the BAPD are used to speculate the formation and evolution of clusters in the early stages of precipitation. Some conclusions are drawn as follows:

1. $\beta^{\prime \prime}$ precipitates present a three-dimensional coherency strain-field with a higher number density during the nonisothermal aging treatment, which provides the most significant obstacles for the dislocation movement and thus results in the maximum strengthening effect in the $\mathrm{Al}-\mathrm{Mg}-$ Si-Cu 6005A alloy.

2. The SVBE and BAPD analysis confirm that Si atoms play an important role in controlling the numbers density of $\mathrm{Mg} / \mathrm{Si}$ co-clusters, and the excess $\mathrm{Si}$ atoms provide the increased number of nucleation sites for the subsequent precipitates to strengthen and improve the precipitation rate.

3. According to the difference of binding energy and the microstructural evolution under non-isothermal aging, the precipitation sequence during the early precipitation in Al-
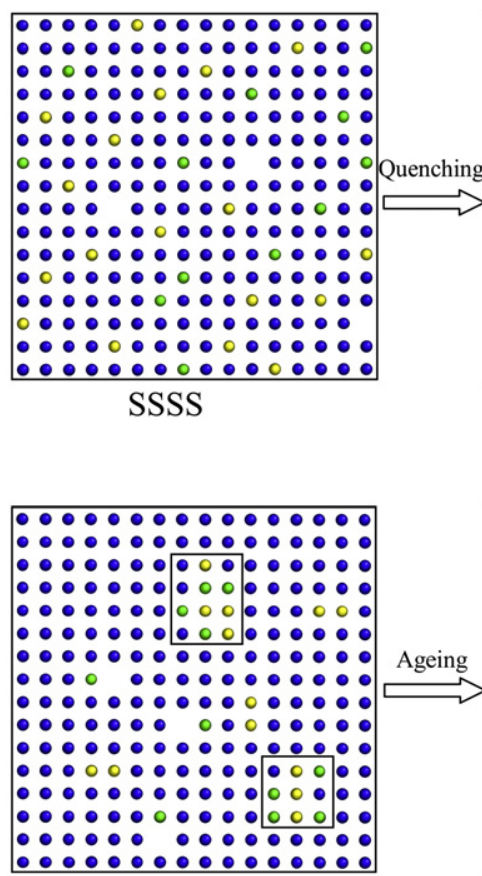

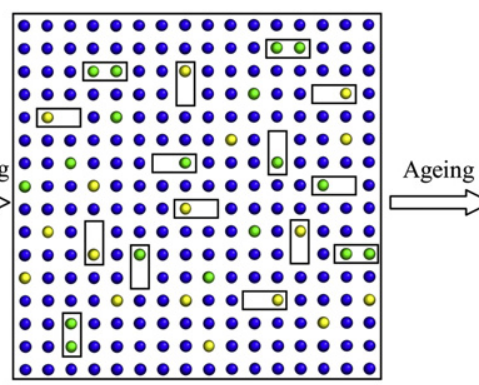

Mg-v, Si-v pairs and

Mg clusters

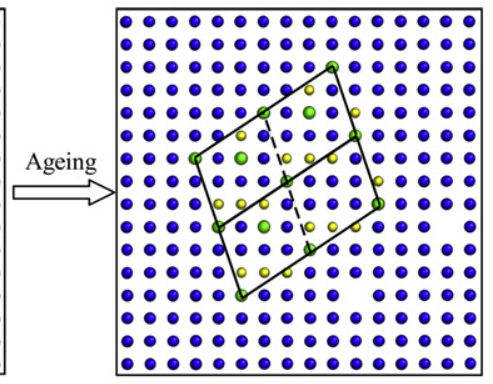

GP zones

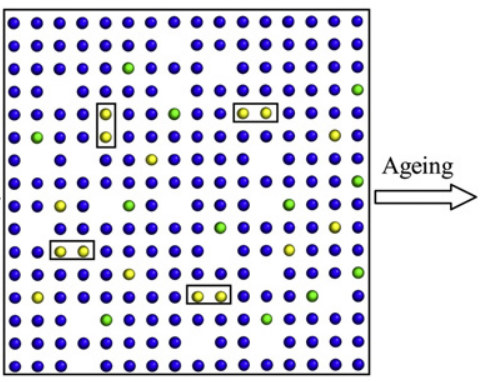

$\mathrm{Mg}$ clusters are dissolved and

Si clusters are precipitated

$\mathrm{Mg}$ atoms segregate into the existing

$\mathrm{Si}$ clusters to form $\mathrm{Mg} / \mathrm{Si}$ co-clusters

$$
\begin{array}{ll}
\text { - } \mathrm{Mg} \\
\text { - } \mathrm{Al} \\
\text { - } \mathrm{Si}
\end{array}
$$

Fig. 5 - Schematic diagrams showing the model of precipitation evolution from SSSS to GP zones in the early stages of precipitation in the Al-Mg-Si-Cu 6005A alloy. 
Mg-Si-Cu 6005A alloy can be described as: SSSS $\rightarrow$ Si-v pairs, $\mathrm{Mg}-\mathrm{v}$ pairs and $\mathrm{Mg}$ clusters $\rightarrow \mathrm{Si}$ clusters and dissolution of $\mathrm{Mg}$ clusters $\rightarrow \mathrm{Mg}$ atoms diffusion into the existing Si clusters $\rightarrow \mathrm{Mg} / \mathrm{Si}$ co-clusters $\rightarrow \mathrm{GP}$ zones.

\section{R E F E R E N C E S}

[1] Fridlyander IN, Sister VG, Grushko OE, Berstenev VV, Sheveleva LM, Lvanova LA. Aluminium alloys: promising materials in the automotive industry. Metal Sci Heat Treat 2002;44:356-70.

[2] Biswas A, Siegel DJ, Wolverton C, Seidman DN. Precipitates in $\mathrm{Al}-\mathrm{Cu}$ alloys revisited: atom-probe tomographic experiments and first-principles calculations of compositional evolution and interfacial segregation. Acta Mater 2011;59:6187-204.

[3] Esmaelli S, Wang X, Lloyd DJ, Poole WJ. On the precipitation-hardening behaviour of the Al-Mg-Si-Cu alloy AA6111. Metall Mater Trans A 2003;34:751-63.

[4] Cao LF, Rometsch PA, Couper ML. Effect of pre-ageing and natural ageing on the paint bake response of alloy AA6181A. Mater Sci Eng A 2013;571:77-82.

[5] Ringer SP, Hono K. Microstructural evolution and age hardening in aluminium alloys: atom probe field-ion microscopy and transmission electron microscopy studies. Mater Charact 2000;44:10-131.

[6] Matsuda K, Ikeno S, Uetani Y, Sato T. Metastable phases in an Al-Mg-Si alloy containing copper. Metall Mater Trans A 2001;32:1293-9.

[7] Chakrabarti DJ, Laughlin DE. Phase relations and precipitation in Al-Mg-Si alloys with $\mathrm{Cu}$ additions. Prog Mater Sci 2004;49:389-410.

[8] Wang X, Esmaeili S, Lloyd DJ. The sequence of precipitation in the Al-Mg-Si-Cu alloy AA6111. Metall Mater Trans A 2006;37:2691-9.

[9] Yang WC, Wang MP, Zhang RR, Zhang Q Sheng XF. The diffraction patterns from $\beta^{\prime \prime}$ precipitates in 12 orientations in Al-Mg-Si alloy. Scripta Mater 2010;62:705-8.

[10] Yang WC, Wang MP, Sheng XF, Zhang Q, Huang LP. Precipitate characteristics and selected area diffraction patterns of the $\beta^{\prime}$ and $Q^{\prime}$ precipitates in Al-Mg-Si-Cu alloys. Philos Mag Lett 2011;91:150-60.

[11] Jacobs MH. The structure of the metastable precipitates formed during ageing of an Al-Mg-Si alloy. Philos Mag 1972;26:1-13.

[12] Arnberg L, Aurivillius B. The crystal structure of $\mathrm{Al}_{x} \mathrm{Cu}_{2} \mathrm{Mg}_{12}-x \mathrm{Si}_{7}$, (h-AlCuMgSi). Acta Chem Scand A 1980;34:1-5.

[13] Wanderka N, Lazarev N, Chang CST, Banhart J. Analysis of clustering in Al-Mg-Si alloy by density spectrum analysis of atom probe data. Ultramicroscopy 2011;11:701-5.
[14] Vissers R, van Huis MA, Jansen J, Zandbergen HW, Marioara $\mathrm{CD}$, Andersen SJ. The crystal structure of the $\beta^{\prime}$ phase in Al-Mg-Si alloys. Acta Mater 2007;55:3815-23.

[15] Chen JH, Costan E, van Huis MA, Xu Q Zandbergen HW. Atomic pillar-based nanoprecipitates strengthen AlMgSi alloys. Science 2006;312:416-9.

[16] Marioara CD, Andersen SJ, Jansen J, Zandbergen HW. Atomic model for GP-zones in $6082 \mathrm{Al}-\mathrm{Mg}-\mathrm{Si}$ system. Acta Mater 2001;49:321-8.

[17] Edwards GA, Stiller K, Dunlop GL, Couper MJ. The precipitation sequence in Al-Mg-Si alloys. Acta Mater 1998;46:3893-904.

[18] Murayama M, Hono K, Saga M, Kikuchi M. Atom probe studies on the early stages of precipitation in Al-Mg-Si alloys. Mater Sci Eng A 1998;250:127-32.

[19] Rometsch PA, Cao LF, Xiong XY, Muddle BC. Atom probe analysis of early-stage strengthening behaviour in an Al-Mg-Si-Cu alloy. Ultramicroscopy 2011;111:690-4.

[20] Chang CST, Banhart J. Low-temperature differential scanning calorimetry of an Al-Mg-Si alloy. Metall Mater Trans A 2011;42:1960-4.

[21] Gaber A, Ali AM, Matsuda K, Kawabata T, Yamazaki T, Ikenno S. Study of the developed precipitates in Al-0.63 $\mathrm{Mg}-0.37 \mathrm{Si}-0.5 \mathrm{Cu}$ (wt.\%) alloy by using DSC and TEM techniques. J Alloys Compd 2007;432:149-55.

[22] Gallais C, Denquin A, Bréchet Y, Lapasset G. Precipitation microstructures in an AA6056 aluminium alloy after friction stir welding: characterisation and modelling. Mater Sci Eng A 2008;496:77-89.

[23] Goel A, Shaaban ER, Melo FCL, Ribeiro MJ, Ferreira JMF. Non-isothermal crystallization kinetic studies on $\mathrm{MgO}-\mathrm{Al}_{2} \mathrm{O}_{3}-\mathrm{SiO}_{2}-\mathrm{TiO}_{2}$ glass. J Non-Cryst Solids 2007;353:2383-91.

[24] Yang WC, Huang LP, Zhang RR, Wang MP, Li Z, Jia YL, et al. Electron microscopy studies of the age-hardening behaviours in 6005A alloy and microstructural characterizations of precipitates. J Alloys Compd 2012;514:220-33.

[25] Özbilen S, Flower HM. Zirconium-vacancy binding and its influence on $\mathrm{S}^{\prime}$-precipitation in an Al-Cu-Mg alloy. Acta Metall 1989;37:2993-3000.

[26] Perry AJ. Solute-vacancy interaction energies and the effect of 0.009 at.\% $\mathrm{Mg}$ on the ageing kinetics of an $\mathrm{Al}-4.01$ at.\% $\mathrm{Zn}$ alloy. Acta Metall 1966;14:1143-56.

[27] Raman KS, Das ESD, Vasu KI. Clustering and solute-vacancy binding energies in Al-4.4\%Zn alloy wt 0.01\% ternary additions. J Mater Sci 1971;61:1367-78.

[28] Perry AJ. Copper clustering and vacancy loss during the quenching of aluminium-copper alloys. Acta Metall 1966;14:305-12.

[29] Somoza A, Petkov MP, Lynn KG. Stability of vacancies during solute clustering in Al-Cu-based alloys. Phys Rev B 2002;65:094107.

[30] Hirosawa S, Sato T, Kamio A, Flower HM. Classification of the role of micro-alloying elements in phase decomposition of $\mathrm{Al}$ based alloys. Acta Mater 2000;48:1797-806.

[31] Kimura H, Hasiguti RR. Interaction of vacancies with Sn atoms and the rate of GP zone formation in an Al-Cu-Sn alloy. Acta Metall 1961;9:1076-8.

[32] Murayama M, Hono K. Pre-precipitate clusters and precipitation processes in Al-Mg-Si alloys. Acta Mater 1999;47:1537-48. 